Revista de Derecho Público: Teoría y Método Marcial Pons Ediciones Jurídicas y Sociales

Vol. 1 | 2021 pp. 129-156 Madrid, 2021 DOI:10.37417/RPD/vol 1 2021529

(C) Hans Michael Heinig (C) Thorsten Kingreen (C) Oliver Lepsius

(C) Christoph Möllers (C) Uwe Volkmann

(C) Hinnerk Wißmann

(C) Gustavo Manuel Díaz González (traducción) ISSN: 2695-7191

Recibido: 09/11/2020 | Aceptado: 26/03/2021 Editado bajo licencia Creative Commons Attribution 4.0 International License.

\title{
WHY CONSTITUTION MATTERS - LA CIENCIA DEL DERECHO CONSTITUCIONAL ANTE LA CRISIS DEL CORONAVIRUS
}

Prof. Dr. Hans Michael Heinig Prof. Dr. Thorsten Kingreen

Prof. Dr. Oliver Lepsius

Prof. Dr. Christoph Möllers

Prof. Dr. Uwe Volkmann

Prof. Dr. Hinnerk Wißmann*

SUMARIO: INTRODUCCIÓN.- 1 . SOBRE LA VOCACIÓN NORMATIVA DE LA CONSTITUCIÓN.- 2. SOBRE EL RANGO Y LA CLASIFICACIÓN DE LOS BIENES JURÍDICO-CONSTITUCIONALES.- 3. SOBRE LA EFICIENCIA POLÍTICA DE LAS PERSPECTIVAS IUSFUNDAMENTALES.— - 4. SOBRE LA SITUACIÓN DE LA LEGISLACIÓN PARLAMENTARIA.- - 5. SOBRE LA NORMACIÓN EJECUTIVA DE LOS GOBIERNOS DE LOS LÄNDER: LOS REQUISITOS CONSTITUCIONALES DE LA ACCIÓN PÚBLICA COMO INSTRUMENTOS DE PROTECCIÓN ESPECÍFICA DE LOS DERECHOS

\footnotetext{
* Los autores son catedráticos de Derecho público, respectivamente, de las Universidades Humboldt de Berlín, Frankfurt, Gotinga, Münster y Ratisbona. Sin perjuicio de la autoría y revisión conjuntas del trabajo, la redacción de los diferentes apartados se ha distribuido del siguiente modo: $H$. M. $H$. se ha encargado del apartado 6; T. K., del apartado 5; O. L., del apartado 4; C. M., de los apartados 7 y 8; U. V., del apartado 2; y $H$. W., de los apartados 1 y 3.

Traducción del original alemán ("Why Constitution Matters - Verfassungsrechtswissenschaft in Zeiten der Corona-Krise", publicado en $J Z, 18 / 2020$, pp. 861-872) a cargo de Gustavo Manuel Díaz González (Universidad de Oviedo). En el texto se mantienen, con autorización del Comité de Dirección de la Revista, las normas de estilo de JZ.
} 
FUNDAMENTALES Y DE FACILITACIÓN DE LA DEMOCRACIA.- 6. SOBRE EL SIGNIFICADO DE LAS FORMAS Y PROCEDIMIENTOS DEMOCRÁTICOS.- 7. CONCLUSIONES

Las medidas adoptadas en el marco de la lucha contra el coronavirus han supuesto una ruptura con respecto a la tradicional comprensión del Estado de Derecho: de la noche a la mañana, y de manera prácticamente global, la lucha contra la COVID-19 se ha erigido en criterio rector único de la praxis política. A la misma se han subordinado derechos de libertad de toda clase; las operaciones comunes de ponderación se han suspendido - en unas condiciones de extraordinaria incertidumbre, con una duración y unas consecuencias imprevisibles_- En el presente estudio se efectúa un balance provisional del papel de la ciencia jurídico-constitucional en una situación de estas características.

\section{INTRODUCCIÓN}

La crisis es la hora del Ejecutivo: esta pertinente y proverbial observación no puede ser la respuesta a cualesquiera cuestiones jurídicas en un ordenamiento constitucional desarrollado. Muy al contrario, inmediatamente se plantea un buen número de interrogantes: ¿Quién determina la existencia de una crisis, así como el momento en que la misma ha finalizado? ¿Quién es exactamente "el Ejecutivo" en un Estado federal participante en procesos de integración supranacional? ¿A qué instrumentos cabe recurrir? ¿Qué bienes jurídicos deben protegerse en una situación de crisis y cuáles, en cambio, deben ceder?

Cuando en marzo de 2020 se impusieron, en cuestión de días, limitaciones radicales en la práctica totalidad de ámbitos de la vida social en Alemania y en la Unión Europea - también en Estados Unidos y en la mayor parte de los países industrializados-, estas cuestiones parecían inoportunas a amplios sectores de la ciudadanía, de la política e incluso de la doctrina constitucional. Las imágenes que llegaban de China, de Bérgamo y muy pronto también de Nueva York eran impactantes: unidades de cuidados intensivos colapsadas, traslado nocturno de féretros en furgones militares, fosas comunes. La propia situación y la respuesta que a la misma debía darse fueron percibidas con una unanimidad inédita: ante la impresión causada por tales noticias y por determinados modelos de actuación para hacer frente a la imparable propagación del virus, resultaba necesario evitar una sobrecarga del sistema sanitario. Tanto las democracias consolidadas como las dictaduras consagraron todos sus esfuerzos a la consecución de dicho objetivo, y paralizaron, en mayor o menor medida, sus respectivos y complejos sistemas socioeconómicos. A este respecto, debe destacarse que ello se produjo en las primeras semanas y meses con una amplia aceptación mediática y social —y, consiguientemente, con un silencio prácticamente total de los científicos críticos de las correspondientes disciplinas, desde la Filosofía a la Sociología, pasando por las Ciencias Políticas y la Teología-. 
En contraste con lo anterior, ya durante los primeros días, en formatos "rápidos", como blogs o columnas de opinión, la doctrina constitucional alemana planteó cuestiones relativas al control de la actuación pública, que, tras un primer momento de parálisis, han ejercido una sensible influencia sobre la jurisprudencia y la política. Este compromiso con el sistema jurídico en situaciones de emergencia no se plantea desde la perspectiva de un absurdo negacionismo o desde el rechazo de la Ciencia. Por el contrario, el mismo responde a la comprensión de que, en situaciones de crisis, el Derecho constitucional debe poseer una capacidad estructural de reacción superior a la de otras ramas del ordenamiento: al mismo no le es desconocido que la existencia del Estado constitucional liberal no se encuentra por sí misma blindada de una vez por todas, sino que precisamente puede ser cuestionada con motivo de la crisis. Por esta razón, desde el primer momento debe tenerse presente la necesidad de justificación, debe exigirse ponderación, deben precisarse los límites aplicables a la gestión de la crisis - con el fin de que la política, la sociedad y la jurisprudencia sean conscientes de lo que está en juego ${ }^{1}$ - En este sentido, en la exposición sucesiva habrán de analizarse, a título ejemplificativo, cuestiones relativas a los parámetros y estándares de control y, en relación con las mismas, el papel de la ciencia del Derecho constitucional en situaciones de crisis.

\section{SOBRE LA VOCACIÓN NORMATIVA DE LA CONSTITUCIÓN}

A la identificación de los estándares jurídico-constitucionales cuya vigencia ha de mantenerse en una situación de crisis precede la cuestión relativa a por qué en tales supuestos deba partirse de la propia Constitución. La respuesta ya no es tan evidente o, al menos, tan clara como podía pensarse con anterioridad al estallido de la crisis. En la teoría política, ha representado desde siempre un reto la narrativa cultivada por Carl Schmitt y sus seguidores contemporáneos, de acuerdo con la cual las situaciones de excepción son el momento de liberación del Ejecutivo con respecto a los vínculos jurídicos por antonomasia ${ }^{2}$. En la realidad política actual, la vigencia de la Constitución es cuestionada con declaraciones como las del canciller austríaco Sebastian Kurz, para quien, frente a la estrategia desarrollada por él mismo para la contención de la pandemia, no pueden oponerse "sutilezas jurídicas" — es decir, razonamientos jurídico-constitucionales ${ }^{3}$ - En el caso de la ciencia jurídica constitucional, de lo

1 En sentido contrario, entre otros, Hase, JZ 2020, pp. 697 y ss., que también ha criticado especialmente a los autores del presente estudio por sus posicionamientos.

2 Carl Schmitt, Politische Theologie, 9. a ed., 2009, pp. 11 y ss.; se adscriben a esta tesis Eric Posnerl Adrian Vermeule, The Executive Unbound, Oxford, 2010; una contestación definitiva de esta doctrina puede verse en Anna-Bettina Kaiser, Ausnahmeverfassungsrecht, 2020, pp. 35 y ss.

3 La cita se toma de Somek, https://www.verfassungsblog.de, 16 de abril de 2020. En un sentido similar, pueden traerse a colación las declaraciones del jefe de la Cancillería Federal Helge Braun de comienzos de mayo de 2020, en las que manifestó su preocupación por la posibilidad de la anulación o de control jurisdiccional de medidas concretas sobre la base del principio de igualdad; cfr. Welt am Sonntag, 3 de mayo de 2020. 
anterior resulta una extendida revisión del propio papel, de acuerdo con la cual los juristas deberían contenerse ante las decisiones que se adoptan durante la crisis, para tomar nuevamente la palabra y emitir sus profundos y bien fundamentados juicios tan solo tras la superación de la misma ${ }^{4}$; en otro caso, sus intervenciones habrían de permanecer, tal y como puede comprobarse en la situación actual, inatendidas 5 . Esta última advertencia se apoya en un rápido repaso de la jurisprudencia histórica de la República Federal, en la que se identifica como origen de la referida falta de consecuencias el sistema de valores y de ponderación fundado con la Sentencia Lüth: el mismo, por razón de su grado de generalidad y abstracción, impondría cada vez más límites y no proporcionaría orientación alguna ante situaciones imprevisibles como la actual ${ }^{6}$.

Lo anterior no afecta exclusivamente a las cuestiones esenciales, aún pendientes de precisión. Presupuesto de los posicionamientos referidos parece ser una comprensión de la Constitución de acuerdo con la cual la misma no regiría en modo alguno en el ámbito de la política, sino tan solo - y, en la medida de lo posible, exclusivamente con carácter retrospectivo- en el contexto judicial, y además no sería jurídica o normativamente vinculante, sino que tan solo obligaría en términos políticos o fácticos ${ }^{7}$. Con ello se desconocería la normatividad de la Constitución, elemento esencial del Estado constitucional de Derecho desde Marbury v. Madison, de una forma tal como no habría podido sospecharse antes del estallido de la crisis. Las Constituciones se fundan en la juridificación del poder político, y lo hacen además en un sentido amplio: todo poder político deriva de la Constitución y se encuentra sujeto a la misma; dicho de otra forma, no existe autoridad alguna al margen de la Constitución ${ }^{8}$. En contra de una ya antigua interpretación constitucional, de la Ley Fundamental resulta con claridad que el anterior principio rige sin sujeción a límite alguno en circunstancias excepcionales, especialmente cuando las mismas, más allá de lo previsto en los arts. 115a y siguientes de la Ley Fundamental para la situación de guerra, no deben ser formalmente declaradas como tales ${ }^{9}$. La normatividad de la Constitución no se ve, de esta forma, suspendida por razón de la crisis, sino que debe precisamente demostrar su eficacia durante la misma; en esencia, en tales situaciones se demuestra en qué medida aquella representa el punto de partida. De no ser así, la crisis se revela como un "constitutional moment" en el que se cuestiona la propia

${ }^{4}$ Cfr. Windhöfel, JZ 2020, p. 457; en el mismo sentido, ya Krüper, https://www.verfassungsblog. de, 2 de abril de 2020: "Se escribe demasiado".

5 En este sentido, Hase, JZ 2020, 697-698.

6 Hase, JZ 2020, 698-699.

7 En este sentido, véase la sólida crítica de Somek, https://www.verfassungsblog.de, 16 de abril de 2020, a las declaraciones del canciller austríaco.

8 Cfr., entre otros muchos, Dieter Grimm, Die Zukunft der Verfassung, 2a edición, 1994, pp. 60-61.

9 Anna-Bettina Kaiser, Ausnahmeverfassungsrecht, 2020, pp. 85 y ss., 126 y ss. y 207 y ss. La posibilidad, prevista en la Ley de protección contra las infecciones, de declaración de una "epidemia de alcance nacional” por parte del Parlamento ( $\$ 5$ IfSG) no entra en conflicto con la anterior consideración; la misma supone, como una suerte de "situación excepcional leve", la introducción de cambios en la legislación ordinaria, pero no es relevante en el nivel jurídico-constitucional. 
vinculación del poder público a la Constitución y que abre la puerta a una futura ruptura con la misma.

Este peligro se ve, por su parte, reforzado por razón de algunas particularidades de la cultura constitucional federal-republicana que pueden, a su vez, resultar vagamente de la Sentencia Lüth; las mismas guardan, sin embargo, escasa relación con el sistema de valores y ponderación de tipo jerárquico y ubicuo al que la resolución referida se ha visto vinculada desde tribunas doctrinales críticas ${ }^{10}$. Por una parte, la Ley Fundamental —a diferencia de Constituciones como la estadounidense, cuya interpretación se basa principalmente en su texto y en la voluntad de la generación fundadora - no es una Constitución estática, sino en gran medida dinámica, que se adapta a los cambios que experimentan tanto la realidad como los valores sociales; por este motivo - quizá en el caso concreto de forma exagerada, pero en esencia convincentemente-, ha podido ser descrita no tanto como una norma fija, sino como un "proceso" ${ }^{11}$. Estas Constituciones son, por naturaleza, y con independencia de las cláusulas de intangibilidad que las mismas puedan incorporar, más susceptibles de desplazamiento y flexibilización, incluso en sus principios esenciales; por este motivo, sería aún más importante insistir en ello — lo que, dicho lisa y llanamente, tampoco en época de crisis tiene lugar fácilmente-. Ello es así también precisamente porque, a diferencia de los sistemas constitucionales en los que durante la situación de urgencia se declara, con carácter formal, la vigencia - temporal- de normas diferentes de las anteriores, la actual situación de excepción en Alemania pasa, como tal, inadvertida al Derecho constitucional, y la lucha frente a la misma se inserta en el marco jurídico ordinario. Lo diferente en este caso desde la perspectiva de los estándares constitucionales es posiblemente el elemento temporal. Y, si se expresan tales temores, es ante todo porque se persigue evitar que los mismos se hagan realidad.

$\mathrm{Si}$, por el contrario, lo anterior se tiene por irrelevante, se pasará por alto, junto a la resonancia de tales advertencias en el círculo de los decisores políticos y en la burocracia ministerial, el significado que la Constitución tiene para la sociedad de este país. Precisamente esta relevancia expone al ordenamiento a mayores peligros. La cultura política de la República Federal ha sido, ciertamente, una cultura con una fuerte tradición constitucionalista, en la medida en que el argumento constitucional está siempre presente y en que los debates sociales más relevantes se reconducen siempre a la Constitución ${ }^{12}$. Ello no deja de presentar inconvenientes, puesto que

${ }_{10}$ Hase, JZ 2020, pp. 698-699.

11 Peter Häberle, Verfassung als öffentlicher Prozess, 3.a ed., 1998; las bases de dicha comprensión se encuentran en Rudolf Smend, Verfassung und Verfassungsrecht, 1928, texto hoy recogido en Rudolf Smend, Staatsrechtliche Abhandlungen und andere Aufsätze, 4. ${ }^{a}$ ed., 2010, pp. 191 y ss. En el Derecho constitucional norteamericano, esta comprensión se correspondería con la - hoy minoritaria — tesis de la "living constitution"; cfr. al respecto Howard Lee McBain, The Living Constitution, 1948, así como la teoría contraria de William H. Rehnquist, "The Notion of a Living Constitution", Texas Law Review, 54 (1976), pp. 693 y ss.

${ }_{12} \mathrm{Al}$ respecto, entre otros muchos, Matthias Jestaedt, Phänomen Bundesverfassungsgericht, en: Lepsius/Jestaedt/Möllers/Schönberger, Das entgrenzte Gericht, 2011, pp. 85-86. 
promueve una politización del debate y una actitud que la clase política prefiere no corregir. Sin embargo, el fenómeno se inserta en el contexto social en el que la ciencia jurídica constitucional opera en este país. Desde la perspectiva externa de la Ciencia Política, la Constitución ha sido correctamente caracterizada como un medio a través del que la sociedad se describe a sí misma y negocia sus ideas y aspiraciones políticas centrales ${ }^{13}$. Las diferentes teorizaciones sobre la Constitución tratan siempre sobre la propia representación de la sociedad, y plantean debates acerca de posibles cambios en la interpretación jurídica que, a su vez, pueden repercutir en el contenido de la Constitución a largo plazo. También en el contexto actual se reproducen estas discusiones, como demuestra la controversia relativa a la supraordenación constitucional, defendida por el presidente del Parlamento, de la dignidad humana sobre el derecho a la vida ${ }^{14}$. ¿Por qué habría la Ciencia jurídica constitucional de abstenerse voluntariamente de tomar parte en tales controversias?

\section{SOBRE EL RANGO Y LA CLASIFICACIÓN DE LOS BIENES JURÍDICO-CONSTITUCIONALES}

Si se atribuye al ordenamiento constitucional $-y$, particularmente, a la Ley Fundamental - también en el contexto de la crisis una relevancia central, desde diferentes perspectivas, debe en primer lugar considerarse la forma en que los bienes jurídicos han sido percibidos y confrontados entre sí. En este sentido, ya a comienzos de 2020 se extendería, a modo de "lección básica de Derecho Constitucional" 15, la siguiente interpretación: "El derecho a la vida y a la integridad física es un derecho fundamental. En una situación de pandemia el mismo se impone sobre los demás derechos fundamentales. Si no se sobrevive a una pandemia, dejan de disfrutarse los derechos de libertad" ${ }^{16}$. Una fórmula como la reproducida se basa y pretende avanzar, al menos implícitamente, sobre un consenso tradicional: el Derecho constitucional representa en todo momento el parámetro de justificación decisivo de la acción estatal; la política no se desvincula del marco diseñado por la Ley Fundamental, sino que se conecta con sus prescripciones ${ }^{17}$. Consecuentemente, se ha subrayado y

13 Uno de los resultados centrales del grupo de investigación de Dresden "Institucionalidad e historicidad"; cfr. Hans Vorländer, Integration durch Verfassung?, en: Vorländer (Hrsg.), Integration durch Verfassung, pp. 23 y ss.; en el mismo sentido, vid. los razonamientos de André Brodocz, Die symbolische Dimension der Verfassung, 2003.

14 Vid. la entrevista a Wolfgang Schäuble en Tagesspiel de 26 de abril de 2020, https://www.tagesspiel.de/politik/bundestagpraesident-zur-corona-krise-schaeuble-will-dem-schutz-des-lebens-nichtalles-unterordnen/25770466.html.

15 Rüdiger Soldt, https://www.faz.net/aktuell/politik/inland/soeder-und-kretschmann-gegen-fruehe-lockerungen-bei-corona-16738743.html.

16 Declaraciones del Presidente del Consejo de Ministros Winfried Kretschmann de 23 de abril de 2020 en Ulm, cfr. Rüdiger Soldt, https://www.faz.net/aktuell/politik/inland/soeder-und-kretschmanngegen-fruehe-lockerungen-bei-corona-16738743.html.

17 La fórmula de Carl Schmitt ("La soberanía la ostenta quien decide en las situaciones excepcionales"; vid. supra, nota al pie 2) ha tenido hasta nuestros días en Alemania un efecto fundamental y 
se subraya con frecuencia que el restablecimiento de la protección de los derechos fundamentales es incontrovertible ${ }^{18}$. De todos modos, debe darse aún respuesta a la cuestión relativa a si la hipótesis material de la primacía absoluta o al menos temporal de determinados bienes jurídicos — concretamente, la vida y la integridad física - es correcta o si la misma puede o no sostenerse seriamente con aplicación de los estándares jurídico-constitucionales vigentes hasta hoy. Y, desde una perspectiva más amplia, debe también reflexionarse sobre si es convincente la comprensión de que los derechos de libertad pueden verse, en la práctica, suspendidos sin consecuencias, para ser posteriormente recuperados.

En este sentido, debe identificarse, en primer lugar, el fin último de la lucha contra la pandemia: al comienzo de la crisis, sobre todo las imágenes que llegaban de Bérgamo y de Nueva York fueron utilizadas como demostración de que en los Estados industrializados (es decir, "entre nosotros") podría asistirse a un colapso del sistema sanitario, incluso de que el mismo sería, como consecuencia de la rapidísima propagación del virus, inevitable ${ }^{19}$. De esta forma, los hospitales del país se adaptaron preventivamente a una situación de emergencia; se instalaron nuevas unidades de cuidados intensivos en hangares de aeropuertos; se adquirió material higiénico-sanitario de toda clase en un mercado internacional despiadado. A la vista de que los datos relativos a los síntomas y fallecimientos causados por la enfermedad se mantenían bajos en comparación con los de otros países, se abrió paso con fuerza otro argumento: en la medida en que en el Estado constitucional liberal debe protegerse siempre la

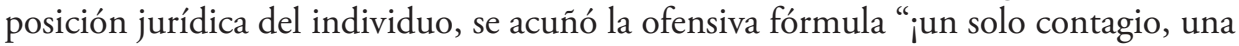
sola muerte es inaceptable!" 20 . A tal fin se parte, desde la perspectiva de la dogmática jurídico-constitucional, de que vida y salud no son tan solo derechos fundamentales de defensa, sino que, en relación con los mismos, al Estado se impone un correlativo deber de protección: el Estado, por lo tanto, no solo tendría vedado lesionar la vida y la salud de los ciudadanos, sino que debería, asimismo, garantizar la inexistencia de riesgos para las mismas. Este salto de la visión global a la perspectiva del individuo supone un cambio decisivo, por cuanto por definición es imposible alcanzar el objetivo de la lucha contra la pandemia, entendido como erradicación total del virus, y consecuentemente al mismo se atribuye, con carácter ilimitado, desde una perspectiva tanto temporal como material, no solo la condición de criterio de validez, sino también la de fundamento de la obligatoriedad de la adopción de determinadas medidas.

duradero. Para una lectura crítica de la misma, cfr. Hasso Hofmann, Der Staat 44, 2005, pp. 171 y ss., especialmente pp. 187 y ss.

18 También en este punto es representativa la declaración gubernamental de 9 de abril de 2020 de Winfried Kretschmann: "Todo esto es temporal. Cuando se supere la crisis, la Constitución será puesta a prueba, porque en ese momento habremos de maximizar nuevamente los derechos con la misma radicalidad con que ahora los limitamos".

19 Esta finalidad es subrayada igualmente por Hase, JZ 2020, p. 698.

20 Ya el 29 de marzo de 2020 se pronunció en estos términos el primer ministro Markus Söder: https:// www.idowa.de/inhalt.bayern-soeder-laedt-zu-pressekonferenz-weitere-beschraenkungen.30b2d0e745cf-465b-9dc2-c3d8c777ac07.html. 
La cuestión relativa a si el referido deber estatal de protección de cada vida, así definido, encuentra o no límites constitucionales depende, en primer término, de los bienes jurídico-constitucionales que se le opongan: estos abarcan desde los derechos de libertad o de primera generación, literalmente suspendidos con carácter temporal (libertad de reunión, libertad religiosa, libre desarrollo de la personalidad, libertad de circulación), pasando por las garantías "legales" del empleo y de la propiedad, que se han visto muy intensamente afectadas por razón de las prohibiciones y las limitaciones al desarrollo de actividades comerciales, hasta los propios derechos a la salud y a la vida, sacrificados por la paralización de tratamientos médicos a gran escala, como consecuencia, por ejemplo, de la cancelación de intervenciones quirúrgicas o de medidas de rehabilitación, así como de la limitación de los cuidados a las personas mayores y con discapacidad. Junto a ello, se adoptaron medidas limitativas de derechos legales en los ámbitos educativo y de formación profesional, que el Estado había reconocido en los últimos ańos, entre otros motivos, con el objetivo de obtener mejoras en materia de igualdad entre mujeres y hombres. El parón radical de toda la actividad social ha tenido un coste económico al que han sucedido, tras escasas semanas, un discurso propio de tiempos de guerra, relativo a la necesaria "reconstrucción de Europa", y los correspondientes programas de deuda.

Debe destacarse que, en la primera fase de la crisis del coronavirus, brilló por su ausencia toda ponderación de los bienes jurídicos en conflicto. La muerte con infección de coronavirus se convirtió en un tabú cuya erradicación no solo justificaría, sino incluso exigiría el pago de cualquier precio. Tal interpretación, no obstante, se aparta de la dogmática iusfundamental actual. El derecho a la vida no es un "superderecho fundamental", toda vez que es incluso susceptible de limitación como resultado de intervenciones estatales ${ }^{21}$. En primer lugar, el Estado no se encuentra obligado a perseguir una determinada política por razón del deber de protección de la vida del individuo; de hecho, se puede llegar a admitir jurídicamente que una persona muera a manos de otra ${ }^{22}$. El derecho a la salud y a la vida forma parte de un amplio conjunto de derechos y garantías para los que la Ley Fundamental exige el máximo nivel posible de protección. Dicho nivel de protección es, en todo caso, el resultado de un proceso permanente, debatible y revisable de ordenación, limitación, maximización y restablecimiento.

21 Art. 2, apdo. 2, inciso 3 de la Ley Fundamental. Para un repaso detallado sobre las limitaciones estatales, véase Jarass/Pieroth, GG, 16. ${ }^{a}$ ed., 2020, Art. 2 Rn. 86 ff.; en particular, sobre las medidas susceptibles de adopción en el momento final de la vida, Rn. 96, 98.

22 Sobre el tremendo dilema del secuestro de Schleyer, BVerfG, 16.10.1977 - 1 BvQ = BVerfGE 46, 160 = JZ 1977, 150. Sobre la tesis de la obligatoriedad de la protección, cfr. la exposición de Ralf Müller-Terpitz, en: Handbuch des Staatsrechts, vol. VII, 3. a ed., 2009, \$ 147 Rn. 71 y ss. Más concretamente, debería precisarse que, en una situación de pandemia, por regla general las dudas no se plantean desde la perspectiva de la necesidad de protección frente a una actuación de terceros a la que cabe imputar la lesión de un bien jurídico, sino en relación con la (más específica) cuestión relativa a la posible exigibilidad de una actuación estatal; sobre esta diferenciación, cfr. Helmuth Schulze-Fielitz, en: Dreier (Hrsg.), GG I, 3. a ed., 2013, Art. 2 II, Rn. 96. 
Como principio constitucional, la protección de la vida disfruta de una posición especial por razón del hecho de que la vida no puede ser lesionada ni sometida a consideraciones utilitaristas ${ }^{23}$. La supremacía de la salud frente a la libertad que pretende deducirse a partir de lo anterior tiene, sin embargo, un efecto devastador sobre la teoría tradicional de los derechos fundamentales: nuevamente los ciudadanos de todo el mundo se ven obligados a defender o a luchar por su propia libertad para no terminar subyugados. Resulta, en fin, irritante el error de concepto de que la salud individual depende de la actuación estatal. A dicha comprensión se oponen tanto los límites de la acción humana como los muy diversos requisitos de eficiencia de las prestaciones sanitarias.

¿Cabe entonces aducir razones de principio para considerar que, en el contexto de la crisis del coronavirus, los parámetros y estándares habituales de ponderación y jerarquización de los bienes jurídicos no han de ser utilizados? Parece claro que, en términos generales, tanto la política como ciertos sectores de la doctrina jurídicoconstitucional se han visto influenciados por la fuerza de algunas imágenes perturbadoras ${ }^{24}$. Algo más concretos resultan dos aspectos íntimamente conectados con la estructura de la dogmática iusfundamental alemana. Toda vez que el Estado dispone de amplios márgenes de actuación para cumplir con su deber de protección de la vida humana ${ }^{25}$, pareció querer imponerse durante la crisis la errónea conclusión de que aquella amplia capacidad de opción incluía una correlativa libertad para sacrificar o limitar el ejercicio de otros derechos. Esta comprensión debe ser rechazada sin paliativos: la existencia de márgenes de actuación no excluye en modo alguno la sujeción a control de las correspondientes actuaciones ni las dota de una justificación adicional. En este sentido, el error podría resultar de que el problema inicial ("faltan camas de cuidados intensivos") hubiera terminado por confundirse con el —inalcanzable - objetivo de protección de la salud del individuo ("nadie debería llegar a ser paciente de cuidados intensivos"), y del potencial justificativo del primer motivo para la persecución de este último fin.

Una ulterior cuestión central se refiere al pretendido "restablecimiento" de la dimensión externa de las libertades tras la superación de la crisis. Frente a tal reduccionismo, debe advertirse sobre la intensa conexión entre las manifestaciones exterior e interior de la libertad en la Ley Fundamental. El ejercicio exterior o social de la libertad — por ejemplo, la libertad de reunión, o los mismos derechos de propiedad y al empleo- es consustancial a la libre formación de posiciones (internas) propias, con lo que la vigencia de la libertad misma requiere de su expresión o ejercicio externo. El derecho al "libre desarrollo de la personalidad" ha sido interpretado como liber-

${ }^{23}$ Vgl. Udo Di Fabio, en: Maunz/Dürig, GG, 2004, Art. 2 II Rn. 9.

24 Frente al "argumento de Bérgamo", debe señalarse que a diario nos enfrentamos a imágenes de fallecimientos horribles en todo el mundo en relación con los que somos igual de culpables que en el contexto de la pandemia. La limitación de la inquietud al ámbito de la salud pública alemana dota al discurso iusfundamental relativo a la vida y a la salud de un nuevo y amargo regusto, desde la perspectiva del silencio que se mantiene en lo relativo a la estrechez política de miras.

25 Por todos, Thorsten Kingreen/Ralf Poscher, Grundrechte, 36. ${ }^{a}$ ed., 2020, Rn. 488 y ss. 
tad general de actuación, de forma que comprende, entre nosotros — a diferencia de lo que ocurre en la mayor parte de los Estados constitucionales_-, la dimensión exterior de las libertades ciudadanas ${ }^{26}$. Sobre la base de esta interpretación, ha de plantearse, desde una perspectiva tanto política como jurídica, si el núcleo esencial de nuestro ordenamiento liberal no resulta lesionado mientras continúe vigente la libertad interna de pensamiento — toda vez que sus expresiones externas, como la libertad de reunión, de acuerdo con dicha lógica, deviene en un derecho inferior, que debe sacrificarse, en todo caso, en situaciones de incertidumbre-. Tal atribución de un valor creciente a la dimensión interna de los derechos fundamentales, en detrimento de su expresión social o exterior, se traduce, sin embargo, en una confusión esencial en relación con el núcleo de la libertad, puesto que el exterior y el interior se encuentran íntimamente ligados y constituyen una sola entidad: la fe se construye a partir del culto religioso en comunidad; la libertad ideológica, por medio del intercambio de experiencias con nuestros semejantes; el "derecho a la educación", a partir del encuentro en las aulas escolares y universitarias; etc. Por consiguiente, tan solo a través de su ejercicio exterior puede desarrollarse en su plenitud la libertad interior. Cualquier otra lectura conduce a la perversa fórmula de Biedermeier — “(tan solo) el pensamiento es libre" - dañando asi la esencia misma de los derechos fundamentales. En último término, se antoja poco realista considerar que la compleja conexión que se establece entre libertad y responsabilidad no solo puede resultar desactivada, sino también restablecida, sin mayores dificultades.

\section{SOBRE LA EFICIENCIA POLÍTICA DE LAS PERSPECTIVAS IUSFUNDAMENTALES}

Por otro lado, debe subrayarse que los derechos fundamentales no despliegan únicamente sus efectos a posteriori, en la fase de control judicial (a la que sucede la de análisis científico-jurídico). Muy al contrario, los derechos fundamentales y su especifico potencial racionalizador vinculan, en primer término, al legislador y al Ejecutivo - también en situaciones de crisis; de hecho, el art. 1.3 de la Ley Fundamental parte del presupuesto que aquí se defiende_- El Estado de Derecho no funciona tan solo en los casos en que se emite una decisión judicial ${ }^{27}$. ¿Qué sería del mismo si la plenitud de las libertades quedara tan solo garantizada por los mecanismos de protección jurisdiccional? ${ }^{28}$ Esta depende, de facto, de las posibilidades del recurrente:

26 BVerfG, 6.6.1989 - 1 BvR 921/85 = BVerfGE 80, 137, 152 y ss., con el conocido voto particular en sentido contrario de Dieter Grimm, 164 y ss. Los fundamentos de esta decisión se encuentran en BVerfG, 16.1.1957 - 1 BvR 253/56 = BVerfGE 6, 32, 36-37 = JZ 1957, 167.

27 El hecho de que los jueces decidan es, sin embargo, para algunos autores justificación suficiente de que "los mecanismos de protección y los patrones de pensamiento" funcionan; en este sentido, Rixen, Recht und Politik 2/2000, apdo. II.3.

28 El ejercicio del derecho de manifestación terminó dependiendo, a comienzos de 2020, de la activación del procedimiento sumario para la protección de los derechos, puesto que las manifestaciones se consideraron como situaciones en las que resultaba imposible la garantía de unas condiciones de 
sus medios financieros, su perseverancia, sus conocimientos sobre el Derecho y la praxis judicial. Centrar exclusivamente la atención en la tutela judicial individual de los derechos fundamentales conduce, de hecho, a una comprensión restrictiva de esos mismos derechos. Un ordenamiento jurídico liberal exige, sin embargo, la aplicación de los derechos fundamentales en la adopción de decisiones por parte de los poderes legislativo y ejecutivo, resultando insuficiente que su eficacia se manifieste en primer lugar a través de la vía ofrecida por el art. 19.4 de la Ley Fundamental ${ }^{29}$. Frente a los diversos poderes, los derechos fundamentales operan en planos diferentes: en el caso del legislativo, en una dimensión general y abstracta; en el del ejecutivo, en una dimensión individual y concreta. El legislador no solo se ve vinculado por los derechos fundamentales desde la perspectiva de la protección de las minorías y de la libertad, sino que se encuentra, además, habilitado para la configuración normativa de esta última. La reserva de ley en materia iusfundamental no alcanza tan solo a la concreción de las respectivas habilitaciones, sino que se extiende también a la conformación de la normativa legal, en pro de un ordenamiento jurídico liberal ${ }^{30}$. Las leyes son, en este sentido, aliadas de la libertad; y los usuales conflictos entre libertades deben abordarse, resolverse y ponderarse en un plano general y abstracto. Por el contrario, la Administración debe observar los derechos fundamentales desde una perspectiva individual y concreta. Toda vez que el conflicto general/abstracto entre derechos fundamentales es afrontado por la Ley, el Ejecutivo puede y debe concentrarse en la resolución del caso concreto, es decir, en alcanzar un equilibrio que tome en consideración el contexto en el que se enfrentan los diferentes intereses dotados de relevancia iusfundamental ${ }^{31}$.

El decisivo canon de proporcionalidad se erige, en este sentido, no solo en instrumento de control de las intervenciones estatales en términos de justicia, sino también en elemento constitucionalmente vinculante de las decisiones, en deber de actuación ${ }^{32}$. Su empleo como parámetro de validez admite, sin embargo, diversas variantes, en función de que sea objeto de control una disposición general/abstrac-

seguridad sanitaria adecuadas y resultaron prohibidas de facto. Al respecto, cfr. los pronunciamientos del BVerfG de 15.4.2020 - 1 BvR 828/20; del VG Münster, 25.4.2020 - 5 L 361/20; y del VGH B-W, 23.5.2020 - 1 S 1586/20.

${ }_{29}$ Tal vez nos hayamos limitado excesivamente en la ciencia jurídica y en la formación de los juristas a la perspectiva del control jurisdiccional, y, con respecto a la dimensión de los otros dos poderes, algunos han podido afimar que la perspectiva de la dirección política ha sido descuidada. Esta era, de hecho, la fuerza motriz de la "nueva ciencia jurídica administrativa", crítica con el "método jurídico" de una dogmática centrada en el control; al respecto, cfr. Ivo Appel y Martin Eifert, Veröffentlichungen der Vereinigung der Deutschen Staatsrechtslehrer, 67 (2008), pp. 226 y ss. y 286 y ss.

30 En palabras de Matthias Jestaedt, Grundrechtsentfaltung im Gesetz, 1999, p. 30: "La vinculación de la ley con respecto a los derechos fundamentales se encuentra, por su parte, dirigida en términos iusfundamentales". Véase, asimismo, Peter Lerche, en: Handbuch des Staatsrechts, vol. V, 1992, \$121.

${ }^{31}$ A esta cuestión se refirieron ya Konrad Hesse y Peter Lerche con sus fórmulas relativas a la concordancia práctica o al equilibrio justo.

32 En relación con esta última caracterización, cfr. Matthias Jestaedt, Verhältnismäßigkeit als Verhaltensmaß, en: Jestaedt/Lepsius (Hrsg.), Verhältnismäßigkeit, 2015, pp. 293-302. 
ta o una decisión individual/ concreta $^{33}$. En el primer caso, se trataría de conflictos entre normas sobre la base de legislative facts (supuestos de hecho susceptibles de agregación estadística o de generalización con base en hipótesis, pero que no pueden ser probados). En el segundo caso, se trata de conflictos entre bienes jurídicos, planteados a partir de la imposición individualizada de límites a la libertad. La crítica de la ponderación como elemento del juicio de proporcionalidad en garantía de los derechos fundamentales implica una confusión de los dos ámbitos. En unos casos se trata de problemas normativos; en otros, de cuestiones de hecho. En el recurso de amparo, el juicio de proporcionalidad se encuentra vinculado en mayor medida por las circunstancias del caso concreto que en el control de constitucionalidad de las leyes: en el supuesto de fiscalización de una intervención específica, la ponderación de bienes jurídicos conduce a la adopción de una decisión puntual, mientras que, en el contexto del control normativo abstracto, subsiste siempre un cierto margen de apreciación, que halla su razón de ser tanto en las características del objeto de enjuiciamiento (la Ley, disposición jurídica general y abstracta) como en la naturaleza del poder controlado (Parlamento). Particularmente, el principio de adecuación se ha caracterizado siempre como una categoría jurídica, con todo lo que ello supone (desde el punto de vista de la ética, la experiencia, la eficiencia, la creatividad, el juego de las mayorías, la garantía de aplicabilidad). La ciencia jurídica tampoco se limita al reducido ámbito jurisdiccional, en el que se resuelven casos concretos, en el que se desarrolla una praxis probatoria y en el que las demás cuestiones se reconducen a la propia responsabilidad de los jueces en cuanto a la interpretación de las normas. Considerar que tan solo las declaraciones basadas en hechos son susceptibles de justificación científica sería demostrativo de una estrecha comprensión de la ciencia. Algunas disciplinas formulan incluso pronósticos con respecto al futuro. En este sentido, durante la pandemia, los virólogos han disputado el terreno a los economistas.

La ciencia jurídica alemana ha experimentado una notable pérdida de influencia social, consecuencia de la limitación de su intervención al debate en torno a la validez o invalidez de las medidas, perdiendo así de vista cuestiones tales como el principio de adecuación, la ética, la experiencia de las instituciones y sus parámetros regulatorios, e incluso la crítica ideológica, y optando por un enfoque pretendidamente teórico y accesorio. El hecho de que la doctrina constitucional alemana se haya centrado en la teoría de los derechos fundamentales se explica también porque, de esta forma, cualquier aspecto que se descuidase podría mantenerse dentro de los contornos de una ciencia jurídica de corte dogmático, basada en el control.

Desde esta perspectiva, debe asimismo subrayarse que los juristas ofrecen criterios de actuación para la adopción de decisiones "correctas", ponderadas y responsables; reclamar la aplicación de estándares iusfundamentales y el desarrollo de actuaciones respetuosas del principio de proporcionalidad supone, ante todo, el empleo de parámetros jurídicos. Por regla general, la acción política busca encontrar una justifica-

33 Sobre esta cuestión, en profundidad, Oliver Lepsius, Chancen und Grenzen des Grundsatzes der Verhältnismäßigkeit, en: Jestaedt/Lepsius (nota al pie 32), pp. 19 y ss. 
ción en criterios científicos, toda vez que estos dotan a las decisiones especialmente relevantes de un grado de legitimidad y acierto que los razonamientos exclusivamente políticos (esto es, el juicio de adecuación apoyado en una mayoría y, consiguientemente, no precisado de justificación material) no les pueden proporcionar. Este papel relativo de la Ciencia ha sido, por lo demás, igualmente destacado por los virólogos, los "auténticos" científicos. Es de lamentar que, en el contexto de la pandemia, la perspectiva científico-jurídica no haya sido apenas tomada en consideración por la clase política. Las causas de dicho fenómeno son variadas. Un temor auspiciado por los medios de masas empujó a los políticos a un grado de exageración del que resultaría difícil liberarse ("están en juego la vida y la muerte"). El conocimiento consustancial a la Ciencia se reconoció tan solo a virólogos y epidemiólogos; incluso los médicos, cuya visión con respecto a la protección de la salud es más amplia, se vieron en determinadas fases relegados a un papel secundario. No alcanza a comprenderse, sin embargo, por qué en un contexto de incertidumbre médica, con un extraordinario impacto social, económico y psicológico, los juristas habrían de considerar que su contribución a la sociedad debía limitarse a mostrarse respetuosos ante los responsables políticos, a adoptar una actitud tímida. Precisamente el ideal es el contrario - y, en este sentido, la pandemia del coronavirus representa un extraordinario ejemplo: el cuestionamiento de la identificación de los bienes jurídicos a proteger supone una contribución a la motivación de las actuaciones- . No estaban en juego la vida y la muerte, sino la protección de la salud, es decir, un bien jurídico relacional, cuya defensa no puede articularse a partir de opciones excluyentes, sino desde puntos de partida flexibles, a fin de resolver los conflictos de intereses y de definir las prioridades. En este sentido, deben tenerse presentes todos los bienes jurídicos en conflicto, puesto que, de otra forma, se termina por atribuir a la protección de la salud un valor absoluto, contrario a su propia naturaleza ${ }^{34}$. Si el foco se pone tan solo en la virología o si se presta en primer término atención a los análisis de riesgo del Instituto Robert Koch (RKI), se pierden de vista los restantes bienes jurídicos. En este sentido, al RKI le resulta prácticamente imposible valorar los riesgos para la salud desde una perspectiva económica, social, cultural o psicológica.

De esta forma, es precisamente obligación de la ciencia jurídica advertir sobre la necesaria toma en consideración de los derechos fundamentales y de la pluralidad de perspectivas relevantes para la adopción de decisiones, así como sobre las relaciones que se establecen entre los derechos de libertad en conflicto. Ello resulta tanto más urgente si se tiene presente que la organización diseñada en el marco de la crisis del coronavirus no proporciona garantías democráticas o procedimentales desde la perspectiva de la toma en consideración del conjunto de intereses afectados. Las decisiones son adoptadas por Ministerios o Gabinetes —estos son ciertamente órganos que, por razón de su especialización funcional, no pueden resolver problemas en los que converge una pluralidad de perspectivas, y que, dada la forma en que se articulan sus procedimientos de toma de decisiones, no estarían en ningún caso en condiciones

\footnotetext{
${ }^{34}$ Cfr. supra, apdo. III.
} 
de hacerlo 35 - Por este motivo, no puede considerarse que el reglamento sea una norma adecuada para resolver conflictos entre derechos fundamentales. Los límites a la delegación normativa previstos en el art. 80 de la Ley Fundamental exigen una consecuente intervención de la Ley. Durante la pandemia se ha configurado un ordenamiento jurídico paralelo, en el que la vida pública ha sido regulada en todos sus ámbitos por disposiciones reglamentarias ${ }^{36}$. Los procesos de toma de decisiones por parte de los gobiernos han dado lugar, asimismo, a la conformación de "coronagabinetes" o de "task forces", precisamente sin participación de los departamentos en cuyos ámbitos competenciales se han producido los principales errores que hoy se evalúan, particularmente desde la perspectiva de las consecuencias del confinamiento (en los ámbitos económico, social, formativo, cultural y de igualdad de género). La comprensión de acuerdo con la cual la gestión de la incertidumbre ha de partir del empleo de parámetros excepcionales se traduce en una reducción significativa de los criterios a valorar en un contexto caracterizado por la inseguridad. En este sentido, los derechos fundamentales dan la señal de alarma.

Otro tanto ocurre con las relaciones de causalidad. Los científicos naturales desconfían de la teoría jurídica de la imputación, que consideran demasiado imprecisa por razón de los elementos valorativos que a la misma se asocian. Sin embargo, precisamente en situaciones de incertidumbre, como la experimentada al comienzo de la pandemia, momento en el que nada concreto se sabía sobre el virus, su forma y velocidad de propagación, la evolución de la enfermedad y las posibles terapias aplicables, la teoría jurídica de la imputación debería haberse erigido en instrumento auxiliar esencial para la adopción de decisiones responsables, puesto que la aplicación de los severos nexos causales propios de las Ciencias naturales obstaculiza la adopción de decisiones. Las medidas de lucha contra el virus se basaron, en cambio, ya en la aplicación de modelos de cálculo diseñados a partir de criterios inciertos, siempre cambiantes (transmisión mediante aerosoles o a través de superficies; en interiores/al aire libre; a través de los niños como vectores de contagio; etc.), ya en la aplicación de la tesis de la equivalencia de condiciones, lo que suponía una burla de los criterios habituales. Estar sentado en el banco de un parque derivó en fuente de peligros no solo para el vecino, sino, en último término, para el entero sistema sanitario; se ordenó el cierre de floristerías y librerías, sin imposición de distancias mínimas o límites de aforo. En este sentido, el principio de proporcionalidad facilita criterios para la clarificación de los nexos causales inciertos. Dicho con otras palabras, si los principales parámetros de decisión no son claros, el principio de proporcionalidad permite hacer frente a la incertidumbre.

Por último, debe hacerse referencia al elemento temporal, dotado igualmente de relevancia iusfundamental. La estructura decisoria del principio de proporcionalidad examina los derechos fundamentales desde una perspectiva maximizadora: cuanto

35 Cfr. Gärditz/Abdusalam, GSZ 2020, p. 108.

${ }^{36} \mathrm{Al}$ respecto, vid. infra, apdos. V y VI. Sobre las estructuras paralelas, cfr. asimismo Lepsius, Recht und Politik, 3/2020. 
más intensa es la intervención, mayores resultan las exigencias de justificación; cuantas más circunstancias hayan de valorarse, más severo será el juicio de adecuación y necesidad y más precisa y vinculada al resultado final será la ponderación de bienes jurídicos. Los juristas pueden, por consiguiente, servirse de una dinámica del conocimiento en el tiempo, puesto que sus parámetros de decisión les permiten tomar simultáneamente en consideración una pluralidad de elementos, valorar los nexos causales y las posibles contingencias, es decir, también los déficits de conocimiento, a lo largo de todo el proceso.

Las categorías iusfundamentales se ponen a prueba, por lo tanto, también en el momento de adopción de decisiones, no solo en la fase de control, y vinculan también en situaciones de incertidumbre, puesto que la interrelación de los elementos de juicio puede compensar los déficits de conocimiento, lo que comporta una mayor o menor flexibilidad en la ponderación de determinados elementos. La postura contraria, de acuerdo con la cual las actuaciones (y los controles) deben desarrollarse en primer término sobre la base de certezas absolutas, tratándose de una situación de riesgo, conduce inevitablemente a la adopción de decisiones erradas, puesto que el conocimiento surge, precisamente, a partir de la experiencia ${ }^{37}$. Para asegurar el acierto de las decisiones que han de adoptarse en ámbitos en los que se reconocen amplios márgenes de apreciación, deviene indispensable la toma en consideración de una pluralidad de perspectivas. Así, junto a los virólogos, deben intervenir tanto médicos sociales como juristas. Es representativa, en este sentido, la Sentencia Gütersloh del OVG de Münster, por la que se declaró la nulidad de un reglamento por vulneración del principio de proporcionalidad tan solo unas horas después de su entrada en vigor ${ }^{38}$. Desde la perspectiva de la imbricación del referido principio y de los derechos fundamentales, se aplicaron parámetros decisorios que condicionaban intensamente la actuación política, exigiendo la adopción de medidas más específicas y temporalmente limitadas: en este sentido, se afirmó la necesidad de que las mismas se extendieran a los territorios en los que se hubiera detectado un concreto nivel de transmisión, no a la totalidad de aquellos a los que alcanzaran las correspondientes potestades de intervención, así como el deber de previsión de mecanismos de vigilancia y control. ¿Cómo podría la política garantizar la protección absoluta de la salud y de la vida, cómo podría actuar ante los temores inoculados a la sociedad o ante las expectativas, excesivamente altas, generadas por los medios? ¿Cómo se construye un discurso relativo a los riesgos tolerables? En este sentido, la conexión con los derechos fundamentales proporciona al sistema elementos de juicio, puesto que amplía y orienta cualitativamente los criterios decisorios. Los jueces no pueden, dada la limitación de su actuación, hacer frente a esta problemática por sí solos, toda vez que su intervención se produce una vez que la correspondiente decisión ha sido ya adoptada. Alzar la voz por los derechos fundamentales es aquí un acto obligado para la ciencia jurídica en beneficio del conjunto de la sociedad.

37 Al respecto, véase la clásica exposición de John Dewey, Die Suche nach Gewißheit, 1998 (1929), pp. 41, 50 y ss., y 72 .

38 OVG Münster, 29.6.2020 - 13 B 940/20.NE. 


\section{SOBRE LA SITUACIÓN DE LA LEGISLACIÓN PARLAMENTARIA}

La vocación normativa de la Constitución en situaciones de incertidumbre alcanza asimismo - y, quizás, especialmente- al Derecho constitucional organizativo, en la medida en que este incorpora las reglas fundamentales sobre la forma y procedimiento de adopción de decisiones políticas. La introducción de modificaciones normativas en este ámbito al amparo de la actual situación excepcional trascendería el contexto presente de crisis.

En marzo de 2020, la "hora del Ejecutivo" incidió directamente sobre la legislación relativa al control de las infecciones. Finalmente, la "hora" terminaría por convertirse en meses. El $\$ 5.2$, apdo. 1, de la Ley de protección contra infecciones (IfSG) habilita al Ministerio de Sanidad para, entre otros aspectos, declarar la inaplicación excepcional de la propia Ley de protección contra infecciones (subapdo. 3), de la Ley del medicamento, de la Ley de estupefacientes, de la Ley de farmacias, del Título V del Código de Seguridad Social, de la Ley sobre transfusiones, así como de otras disposiciones no especificadas en materia de producción de medicamentos y protección laboral (subapdo. 4). Asimismo, el Ministerio puede adoptar, mediante reglamento, "medidas para garantizar la continuidad en la prestación de servicios sanitarios en ambulancias de soporte digital avanzado, farmacias, hospitales, laboratorios, instituciones de previsión y de rehabilitación y en otras categorías de centros sanitarios, excepcionando la aplicación de la normativa legal vigente" (subapdo. 7), así como "disposiciones excepcionales" en relación con previsiones no especificadas de la "legislación laboral aplicable a las categorías profesionales de los servicios de salud" (subapdo. 10). De acuerdo con lo establecido en el $\$ 5.4$, apdo. 1, de la IfSG, la vigencia de los reglamentos aprobados por esta vía finalizará una vez que el Parlamento declare la superación de la epidemia en el territorio nacional $(\$ 5.1$, apdo. 2 , de la IfSG) y, a más tardar, el 31 de marzo de 2021, sin exclusión de la posibilidad de ulteriores prórrogas.

La introducción de "excepciones" o "inaplicaciones puntuales" de leyes parlamentarias no especificadas mediante reglamentos incide directamente sobre los principios constitucionales que disciplinan el sistema de relaciones entre ambos tipos de fuentes normativas. De acuerdo con lo establecido en el art. 80.1, apdo. 1, de la Ley Fundamental, las leyes pueden autorizar deslegalizaciones, esto es, la adopción de reglamentos en los supuestos en los que, de conformidad con lo previsto en el apdo. 2, se determinen el contenido, la finalidad y el alcance de la correspondiente habilitación. El art. 80.1 de la Ley Fundamental se inscribe en el contexto de las "dolorosas experiencias que han jalonado la historia constitucional alemana" ${ }^{39}$ y cumple una función de "especificación de los principios de legalidad, de separación de poderes $[\ldots]$ y democrático" ${ }^{40}$. El mismo debería, en palabras de Fritz Ossenbühl, "poner fin a la 'legislación delegada' y evitar una traslación silenciosa de la potestad

\footnotetext{
39 Fritz Ossenbühl, en: Handbuch des Staatsrechts, vol. V, 3.aed., 2007, \$103 Rn. 2.

40 BVerfG, 19.9.2018 - 2 BvF 1/15, 2 BvF 2/15 = BVerfGE 150, 1, 100.
} 
normativa al Ejecutivo, así como la transformación conexa a la misma del sistema constitucional" ${ }^{41}$. Por estos motivos, el Parlamento no puede, de acuerdo con el $B V \operatorname{verfG}$, "desprenderse, por medio de una habilitación en blanco al Ejecutivo, de su responsabilidad legislativa, abdicando así de sus funciones" ${ }^{42}$.

El referido parámetro constitucional había permanecido hasta hoy indiscutido, y no parece en modo alguno temerario considerar cubiertas por su ámbito de aplicación disposiciones como el $\$ 5.2$, apdo. 1, de la IfSG, que habilitan al titular de la potestad reglamentaria para apartarse de las mismas. El $B \operatorname{Verf} G^{43}$ y la doctrina mayoritaria ${ }^{44}$ se han posicionado, en principio, a favor de la validez de tales reglamentos sustitutivos de la Ley. Pero el deber de predeterminación normativa que resulta del art. 80.1, apdo. 2, de la Ley Fundamental, establece límites a dicha operación. El legislador parlamentario debe "decidir por sí mismo, mediante la habilitación, qué aspectos deben o pueden ser regulados mediante reglamento". El $B V \operatorname{erf} G$ ha delimitado diversas dimensiones del referido requisito: una reserva de decisión autónoma del Parlamento, que "[debe] establecer y especificar los límites de tal regulación, así como los fines a cuya consecución la misma debe orientarse"; una obligación de programación normativa, de la que resulta el deber del legislador de definir un "programa" que el poder delegado debe hacer efectivo a través del ejercicio de la habilitación; y, en último lugar, el a nuestros efectos particularmente relevante deber de previsibilidad, de acuerdo con el cual ya sobre la base de la habilitación debe poder determinarse "en qué casos y con qué objetivos puede hacerse uso de la misma, así como el posible contenido de los reglamentos adoptados con base en la delegación, de manera que los destinatarios de la norma puedan adecuar su comportamiento a la misma" ${ }^{45}$. El $B V \operatorname{erf} G$ ha llegado incluso a descartar que el reglamento pueda "plasmar la voluntad política originaria del Ejecutivo" ${ }^{46}$.

El deber de predeterminación normativa del art. 80.1, apdo. 2, de la Ley Fundamental instituye así no solo un derecho de configuración política, sino también, desde la perspectiva de su posición frente al Ejecutivo, una obligación de regulación a cargo del legislador parlamentario. La misma vincula con mayor intensidad la habilitación para la adopción de reglamentos sustitutivos de la Ley, puesto que los mismos pasan a ocupar el lugar de una regulación dictada como expresión de la voluntad legislativa. Este es el razonamiento del $B \operatorname{Verf} G$ cuando declara que se han excedido los

41 Fritz Ossenbühl, en: Handbuch des Staatsrechts, vol. V, 3.aed., 2007, \103 Rn. 2.

42 BVerfG, 19.9.2018 - 2 BvF 1/15, 2 BvF 2/15 = BVerfGE 150, 1, 100.

43 BVerfG, 6.5.1958 - 2 BvL 37/56, 2 BvL 11/57 = BVerfGE 8, 155, 170-171; y BVerfG, 4.5.1977 - 2 BvR 509/96 y 2 BvR 511/96 = NJW 1998, p. 670.

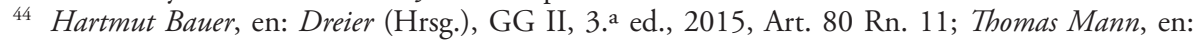

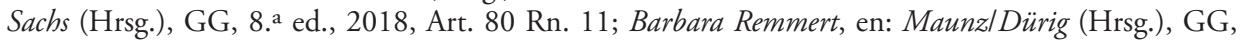
2013, Art. 80 rn. 90, 99; Astrid Wallrabenstein, en: von Münch/Kunig (Hrsg.), GG II, Ar. 80 Rn. 10. En contra de la referida doctrina, véase Arnd Uhle, Parlament und Rechtsverordnung, 1999, pp. 420 y ss.

45 BVerfG, 19.9.2018 - $2 \mathrm{BvF} 1 / 15,2 \mathrm{BvF}$ 2/15 = BVerfGE 150, 1, 101; en el mismo sentido, Michael Brenner, en: von Mangoldt/Klein/Starck GG, 7.a ed., 2018, Art. 80 Rn. 40; Jarass/Pieroth, GG.,

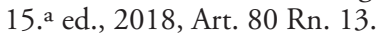

46 BVerfG, 8.6.1988 - 2 BvL 9/85, 2 BvL 3/86 = BVerfGE 78, 249, 273; cursiva en el original. 
límites para considerar que un reglamento sustitutivo de la Ley es válido, "en la medida en que el legislador atribuye carácter subsidiario a disposiciones dotadas de una significación y de un alcance tales que suponen, dentro de la estructura del Estado, una redistribución del peso específico del poder legislativo y de la Administración” ${ }^{47}$. Consiguientemente, hasta hoy la jurisprudencia ha admitido las deslegalizaciones, esto es, la validez de las habilitaciones legales para la adopción de reglamentos sustitutivos de las leyes únicamente si tales deslegalizaciones especificaban cuáles habían de ser las disposiciones legales afectadas por las correspondientes derogaciones ${ }^{48}$. La limitación a previsiones normativas concretas en las habilitaciones legales es necesaria para garantizar la primacía de la configuración política del legislador. La misma se orienta igualmente a la preservación de la claridad como exigencia conexa al Estado de Derecho: sin embargo, el $\$ 5.2$, apdo. 1 , de la IfSG introduce una licenciosa "legislación paralela" ${ }^{49}$, que imposibilita determinar con claridad si la regulación prevista en la "ley principal" se encuentra realmente vigente.

Frente a la crítica de tales desplazamientos se esgrime la existencia de reconocidas cláusulas experimentales ${ }^{50}$. No obstante, ni la existencia de disposiciones legales ni expresiones vacías, pretendidamente tecnocráticas (como, por ejemplo, "ámbitos sociales complejos, accidentados y fragmentarios" ${ }^{51}$ ), satisfacen los parámetros constitucionales. Las mismas pierden de vista que en este caso nos encontramos ante un fenómeno diferente, desde una perspectiva conceptual, de las cláusulas experimentales. Las habilitaciones reglamentarias incorporadas por el $\$ 5.2$, apdo. 1 , de la IfSG facultan, sin diferenciación alguna, para la introducción de excepciones y derogaciones con respecto a todas las normas de las leyes sanitarias allí referidas. Toda vez que la propia Ley de protección contra infecciones es mencionada expresamente en el precepto citado, la misma podría resultar igualmente suspendida. A la vista de las normas de rango legal cuya modificación se admite por medio de reglamentos, nos encontramos ante una habilitación en blanco que puede afectar a más de un millar de disposiciones. De lo anterior resulta que las habilitaciones reglamentarias referidas bien incumplen los requisitos para la introducción de "excepciones" o "inaplicaciones" de las leyes (subapdo. 4, letra a; subapdos. 7, 8 y 10), o bien son definidas con una amplitud tal (subapdo. 3: "para garantizar la continuidad de la asistencia sanitaria y el abastecimiento de la población”) que ya no es posible reconocer en qué supuestos y bajo qué condiciones cabe su activación. Una ley susceptible no solo de

47 BVerfG, 6.5.1958 - 2 BvL 37/56, 2 BvL 11/57 = BVerfGE 8, 155, 171.

48 BVerfG, 6.5.1958 - 2 BvL 37/56, 2 BvL 11/57 = BVerfGE 8, 155, 171.

49 Véase la recopilación de los reglamentos adoptados sobre la base del $\$ 5.2$, apdo. 1, de la IfSG en la página web del Ministerio de Sanidad: https://www.bundesgesundheitsministerium.de/service/ gesetze-und-verordnungen.html.

50 Hase, JZ 2020, p. 700. El trabajo, citado por Hase en este artículo, de Volker Maa囚, Experimentierklauseln für die Verwaltung und ihre rechtlichen Grenzen, 2001, considera, en contra de la conclusión alcanzada por Hase, que no cabe aceptar en términos generales la constitucionalidad de tales cláusulas experimentales; cfr. la exposición desarrollada en las pp. 131 y 137 y ss. con respecto al $\$ 11.4$ GO LSA.

${ }^{51}$ Hase, JZ 2020, p. 703. 
concreción, sino también de suspensión por parte de un Ministerio sin sujeción a límite alguno, se sitúa inequívocamente extramuros del deber de predeterminación resultante del art. 80.1, apdo. 2, de la Ley Fundamental ${ }^{52}$.

El referido desplazamiento de potestades decisorias esenciales en materia de derechos fundamentales hacia un Ejecutivo al que no se dota de una orientación legal ha pesado, sin embargo, mucho menos que las restricciones de derechos fundamentales impuestas en forma de toques de queda y limitación de los contactos sociales. La adopción de estas medidas al amparo de habilitaciones reglamentarias ha afectado notablemente al equilibrio horizontal de poderes configurado sobre la base de los principios del Estado democrático de Derecho. Las mismas han debilitado particularmente la acción de la oposición en el Parlamento, excluida por la legislación de la crisis. Desconocer, o incluso ocultar que la crítica, dirigida por vez primera ante los medios, al $\$ 5.2$, apdo. 1 , de la IfSG, no fue solo formulada por los primeros autores que escribieron sobre el particular ${ }^{53}$, sino también por los servicios jurídicos del Parlamento ${ }^{54}$, es la mejor prueba de la necesidad de que la ciencia jurídica constitucional incorpore al debate público, precisamente durante la crisis, los elementos organizativos constitucionales, así como, al igual que en relación con el art. 80.1 de la Ley Fundamental, su contexto histórico y su esencial funcionalidad para el Estado. Se plantea, en este contexto, el riesgo de una petrificación de las "horas" del Ejecutivo. La evidencia de dicho riesgo ha sido puesta de manifiesto por un reciente proyecto de ley del Gobierno de coalición. La propuesta consiste en la inclusión de un nuevo $\$ 52.4$ en la Ley electoral federal (BWahlG), que habilitaría al Ministerio del Interior, Obras Públicas y Vivienda para, en el caso de que se produzca una catástrofe natural o un acontecimiento similar de fuerza mayor, adoptar, sin autorización del Parlamento, una normativa de excepción que permita el nombramiento de los candidatos a las elecciones sin reunión de la asamblea ${ }^{55}$. Parece inevitable la consolidación paulatina de la legislación por medio de reglamentos ministeriales de necesidad. Si bien habría podido decirse que, hasta el momento, el problema afectaba tan solo a aspectos de detalle de la normativa en materia de protección frente a las infecciones (y ni siquiera esto es enteramente correcto, toda vez que se veían igualmente afectadas cuestiones sensibles, acordándose, por ejemplo, una desregulación en el ámbito de las autoriza-

52 Möllers, https://verfassungsblog.de, 26 de marzo de 2020.

53 Gärditz/Abdusalam, GSZ 2020, pp. 114-115; Mayen, NVwZ 2020, pp. 831 y ss.; Michl, JuS 2020, p. 509; en un sentido particularmente crítico, Rixen, NJW 2020, pp. 1103-1104: "si los límites del artículo 80.1, apdo. 2, de la Ley Fundamental [...] se sobrepasan”; mostrándose, cuando menos, escéptico, Meßling, NZS 2020, pp. 323-324. Hasta el momento no se han alzado voces en la doctrina contrarias a la tesis aquí defendida.

54 Parlamento alemán, Servicio Jurídico, Staatsorganisation und $\$ 5$ Infektionsschutzgesetz, WD33000-080/20, p. 7.

55 BT-Drucks. 19/20596.

$(N$. del T.) El nuevo texto del $\$ 52.4$ de la BWahlG fue definitivamente incorporado por la Ley de 28 de octubre de 2020, de modificación de la Ley electoral federal, así como de la Ley de medidas en materia de Derecho de sociedades, de cooperativas, de asociaciones, de fundaciones y de propiedad de la vivienda para hacer frente a los efectos de la pandemia de COVID-19 (BWahlGuä̈ndG). 
ciones para la comercialización de medicamentos), en el momento presente se trata, con la reforma de la BWahlG, de la preservación de la democracia. Si la preparación de las elecciones se deja en manos del Ejecutivo, no se satisface la exigencia del $B V e r-$ $f G$ de previsión de una "estricta regulación de la preparación y el desarrollo de la votación", exigencia que se conecta con el "significado de las elecciones al Parlamento alemán como punto de partida de la entera legitimación democrática y de la garantía de los derechos de sufragio activo y pasivo" ${ }^{56}$.

\section{SOBRE LA NORMACIÓN EJECUTIVA DE LOS GOBIERNOS DE LOS LÄNDER: LOS REQUISITOS CONSTITUCIONALES DE LA ACCIÓN PÚBLICA COMO INSTRUMENTOS DE PROTECCIÓN ESPECÍFICA DE LOS DERECHOS FUNDAMENTALES Y DE FACILITACIÓN DE LA DEMOCRACIA}

No solo la habilitación normativa incorporada por el $\$ 5.2$, apdo. 1 , de la IfSG plantea dudas desde la perspectiva jurídico-constitucional: los $\$ \$ 28$ y ss. y 32 del mismo cuerpo legal han dado igualmente lugar a dificultades en su aplicación práctica. En este sentido, el $\$ 28$ de la IfSG incorpora una cláusula general que responde, con ligeras modificaciones que atienden a su ámbito de aplicación, a la lógica propia del Derecho de policía ${ }^{57}$. El Estado se ve así obligado a adoptar medidas de protección y de prevención ante todo tipo de situaciones en un ámbito tan complejo y potencialmente cambiante como el de las enfermedades infecciosas. Consecuentemente, la IfSG prevé, en primer lugar, una amplia habilitación para la adopción de medidas restrictivas a favor de las autoridades competentes en materia de protección frente a las infecciones $(\$ 28.1$, inciso primero, de la IfSG) — por lo tanto, en la lógica de la Ley Fundamental (art. 83), a favor de las administraciones de los Länder-. La misma introduce, asimismo, una habilitación para la adopción de reglamentos por parte de los gobiernos de los Estados federados ( $\$ 32$ de la IfSG).

Sobre dicha base se impuso el shutdown de la vida pública en Alemania a mediados de marzo de 2020. Originariamente, los instrumentos previstos en los $\$ \$ 28$ y ss. de la IfSG estaban pensados para intervenciones de menor alcance e intensidad. Ciertamente, a comienzos de año, el ordenamiento no preveía otras bases jurídicas o regulaciones de origen parlamentario dotadas de un mayor grado de detalle y amplitud para la adopción de las medidas necesarias a la vista del rápido aumento de casos de infección por COVID-19. De esta forma, en poco tiempo todos los Estados federados introdujeron nuevas obligaciones y prohibiciones de actuación en todos los ámbitos de la vida pública al amparo de los $\$ \$ 28$ y ss. de la IfSG. Algunos Länder optaron, en este contexto, por la adopción de decisiones de alcance general. Sin em-

56 BVerfG, 20.10.1993 - 2 BvC 2/91 = BVerfGE 89, 243, 250-251.

57 Para una visión general sobre esta cuestión, cfr., por ejemplo, Rixen, NJW 2020, pp. 1097 y ss. 
bargo, muy pronto se plantearon dudas en relación con la posibilidad de imposición de obligaciones de actuación de carácter general y abstracto, como las limitaciones de los movimientos, en todo el territorio de los respectivos Estados, por virtud de actos administrativos ${ }^{58}$. De esta forma, el Reglamento devino en instrumento jurídico principal en este contexto. El $\$ 32$ de la IfSG habilita, con esta finalidad, a los gobiernos de los Estados federados, que a su vez pueden dotar de subdelegaciones a los departamentos con competencias en el ámbito sanitario. Al respecto, hasta la fecha no se han producido variaciones.

La referida praxis, que se ha mantenido constante, plantea problemas desde la perspectiva jurídico-constitucional; en este sentido, mientras que la inconstitucionalidad de algunas intervenciones resulta manifiesta, en otros casos la cuestión se sitúa en la frontera entre la invalidez y la conformidad con la Ley Fundamental. Lo anterior resulta de que la principal función de la ciencia jurídica constitucional no es la resolución de casos concretos (ello incluso pese a que la formación jurídica se dirija primordialmente a la misma), sino la de proporcionar descripciones y aclaraciones en relación con los problemas jurídicos, la de observar las potenciales mutaciones en la dogmática y la cultura constitucionales y, en definitiva, la de analizar sus consecuencias para el sistema normativo y la integración política.

La reciente praxis en relación con los $\$ \$ 32$ y 28.1, inciso primero, de la IfSG presenta una extraordinaria relevancia para la doctrina constitucional: los presupuestos jurídico-constitucionales de las habilitaciones normativas a favor del Ejecutivo se orientan a la protección de las prerrogativas del Parlamento — vinculadas a su legitimación democrática, que resulta de la elección directa de sus miembros por el Pueblo- y constituyen al mismo tiempo una manifestación de la teoría de la esencialidad, de base iusfundamental. De esta forma, tanto desde la perspectiva de la legitimación como desde el punto de vista de los derechos fundamentales debe analizarse si y en qué medida la habilitación normativa introducida por el $\$ 32$ de la IfSG satisface los requisitos del art. 80.1, apdo. 1, de la Ley Fundamental, a la luz de la praxis reglamentaria tradicional. En el análisis jurídico, ¿debe tal vez establecerse una separación neta de la fase inicial de la pandemia, durante la que existía un elevado grado de incertidumbre en relación con el avance y la propagación del virus, y una posterior fase de consolidación provisional? ${ }^{59}$ ¿Rige también en la legislación sobre protección frente a las infecciones el principio general del Derecho de policía de acuerdo con el cual las nuevas medidas estándar exigen, tras una fase de experimentación y de autoevaluación, un fundamento legal específico? ${ }^{60}$ Se trata, en este sentido, de cuestiones

58 VG München COVuR, 2020, 163; sobre esta cuestión, vid. asimismo Gärditz/Abdusalam, GSZ 2020, p. 111.

59 Para una reflexión en esta dirección, véase el diálogo entre Hans Michael Heinig y Christian Waldhoff, en: Konrad-Adenauer-Stiftung (Hrsg.), Stresstest für die Verfassungsordnung, 2020, pp. 5, 7 y passim.

60 Sobre la relación entre las cláusulas generales y las medidas estándar, cfr. Friedrich Schoch, en: Friedrich Schoch (Hrsg.), Besonderes Verwaltungsrecht, 2018, pp. 12, 79-80. En la jurisprudencia, véase, por todas, BVerwG NVwZ 2002, pp. 598, 601-602. 
nucleares en relación con la legitimación democrática y la vinculación efectiva de la acción estatal a los derechos fundamentales. Posponer el debate al momento en que la pandemia de la COVID-19 haya sido superada evidencia una extraña comprensión tanto del Derecho constitucional como de su tratamiento científico.

La praxis desarrollada hasta la fecha en relación con la adopción de normas reglamentarias por los Länder para combatir la pandemia ofrece, en todo caso, un material de investigación que trasciende los requisitos de las habilitaciones otorgadas sobre la base del art. 80.1 de la Ley Fundamental: la misma posibilita, en primer lugar, un análisis de las fortalezas y debilidades del federalismo alemán. La federalización de la lucha contra la pandemia — que se ha extendido más allá de la ejecución administrativa, en tanto que ha alcanzado a la adopción de disposiciones normativas- ha permitido acompasar la reacción a las diferentes situaciones regionales ${ }^{61}$. La misma, sin embargo, tal y como ha sido implementada, se ha traducido en una desparlamentarización de la producción normativa — y se ha convertido, por razón de la imposición de severas restricciones al ejercicio de determinados derechos fundamentales, de una intensidad y una extensión sin precedentes desde la entrada en vigor de la Ley Fundamental, en una cuestión vital para la comunidad- ${ }^{62}$.

La referida desparlamentarización respondía a una visión pragmática, comprensible al menos en la fase inicial, en tanto que conexa al objetivo de protección frente a las infecciones de la IfSG. Sin embargo, a medida que avanzaba la propagación del virus y que se profundizaba en el conocimiento científico en relación con su evolución, se hicieron patentes sus "costes" desde la perspectiva constitucional ${ }^{63}$ : la lucha estatal contra la pandemia es, en último término, algo más que una mera ejecución tecnocrática de una serie de pautas de actuación epidemiológica. La misma exige el desarrollo de complejas valoraciones que son, además, objeto de un legítimo debate social. La adopción de normas ejecutivas se diferencia en este sentido de manera notable con respecto a la legislación parlamentaria por razón de su procedimiento de elaboración: el proceso legislativo favorece el debate, ofrece otro escenario para dirimir los conflictos y para — sobre la base de la máxima "legitimación a través del procedimiento" ${ }^{64}$ - generar aceptación social. El procedimiento legislativo constituye una garantía de calidad normativa, pero, por razón de su lentitud, amenaza con hacer fracasar la producción normativa ejecutiva, particularmente si se somete a un concreto departamento a una fuerte presión temporal ${ }^{65}$. Desde la perspectiva de la separación de poderes, la legislación parlamentaria posibilita la diferenciación fun-

61 Gärditz/Abdusalam, GSZ 2020, p. 110; los autores hacen asimismo referencia a los peligros de una federalización competitiva en términos políticos.

62 En relación con la posibilidad de una reparlamentarización sobre la base del artículo 80.4 de la Ley Fundamental, véase Birkner, ZRP 2020, pp. 157 y ss.

63 Sorprendentemente ajeno a estas cuestiones, Hase, JZ 2020, pp. 697 y ss., cuyas reflexiones, antes que diagnóstico, son expresión de una "crisis del pensamiento constitucional" (p. 703).

64 Niklas Luhmann, Legitimation durch Verfahren, 1969.

65 Birkner, ZRP 2020, pp. 157-158, denuncia, ofreciendo ilustrativos ejemplos, una grave falta de recursos humanos. 
cional, característica del Estado de Derecho, entre órganos estatales de producción normativa y de ejecución ${ }^{66}$. Al mismo tiempo, el Parlamento facilita específicamente la posibilidad de toma en consideración de intereses heterogéneos y la consecución de equilibrios adecuados. Por oposición a lo anterior, la praxis reglamentaria desarrollada hasta la fecha en la lucha contra la pandemia amenaza con introducir desequilibrios en la identificación y ponderación de los intereses legítimos, especialmente en los casos en los que una subdelegación actúa en un departamento específico, en sustitución del Gobierno del Land como órgano colegiado. La lógica departamental amenaza con desarrollarse de forma escasamente ponderada y equívoca. Los requisitos previstos en el art. 80.1 de la Ley Fundamental en relación con las habilitaciones normativas al Ejecutivo permiten, desde este punto de vista, garantizar, en términos sistemáticos, que la complejidad de las cadenas de impactos y consecuencias de las intervenciones estatales en las sociedades modernas sea objeto de una reflexión satisfactoria. Recordar tales "servicios" del Derecho constitucional es la misión principal de su tratamiento científico - también, precisamente, en el contexto de una crisis sanitaria, que afecta directa o indirectamente a todos los ámbitos de la sociedad-.

\section{SOBRE EL SIGNIFICADO DE LAS FORMAS Y PROCEDIMIENTOS DEMOCRÁTICOS}

En ocasiones, la ciencia jurídica constitucional reniega de sus propias bases y se orienta a la búsqueda de soluciones a problemas ficticios. La crisis del coronavirus invita al desarrollo de la referida estrategia, en absoluto novedosa y, bajo diversas formas, extendida: partiendo de la diferenciación, cara al realismo jurídico, entre law in the books y law in action 67, pasando por la invocación de la realidad en los debates de Weimar y en fases posteriores ${ }^{68}$, la búsqueda del "ordenamiento" tras la Constitución ${ }^{69}$ llevaría a concluir que las reglas de procedimiento cumplen, en el Derecho público, una finalidad meramente "accesoria" ${ }^{70}$. En este sentido, ¿qué motivo habría para no renunciar a las formalidades con el fin de salvar vidas?

Sin embargo, la diferenciación entre forma y contenido, o incluso entre forma jurídica y realidad política, induce a error. Las formas jurídicas no son neutras con respecto al fondo, y el poder político debe, en el Estado constitucional, reconducirse siempre a las formas. El ministro es ministro por haber alcanzado tal condición a través de un procedimiento constitucional. Precisamente por este motivo, la pretendida necesidad de una acción rápida y decidida, que prescinda de todo formalismo, para la superación de la crisis, no es solo jurídicamente indiscutible, sino que exige un con-

\footnotetext{
66 Christoph Möllers, Die drei Gewalten, 2008.

Roscoe Pound, Law in Books and Law in Action, American Law Review 44, 1910, pp. 12-36.

Oliver Lepsius, Die gegensatzaufhebende Begriffsbildung, 1994.

Carl Schmitt, Politische Theologie, 1922; Hase, JZ 2020, pp. 697, 698 y ss.

70 Christian Quabeck, Dienende Funktion des Verwaltungsverfahrens und Prozeduralisierung,
} 2010. 
trol tanto desde la perspectiva de los hechos como desde un punto de vista práctico. A los ojos del mundo, la amenaza del virus se ha intensificado desde finales de febrero de 2020, sin que se tuviera la impresión, en un momento concreto, de que una determinada medida no habría podido ser adoptada, por razón de su urgencia, a través de un procedimiento parlamentario. Muy al contrario, las decisiones adoptadas en la República Federal fueron el resultado de un procedimiento informal y, sin embargo, no especialmente rápido, de votación de los jefes de gobierno de la Federación y de los Länder. El hecho de que el debate parlamentario pudiera completarse a través de procesos de negociación federal con intervención de los respectivos ejecutivos es ciertamente significativo desde la perspectiva de la estructura del sistema político de la República Federal ${ }^{71}$, pero relativiza, al mismo tiempo, la pretendida necesidad de agilidad en la adopción de decisiones en el contexto de crisis extremas.

La observancia de las formas, procedimientos y requisitos constitucionales, tales como la reserva de ley y los límites a la delegación, deviene especialmente importante precisamente en un momento en el que la política, como consecuencia de la inseguridad general, debe inspirar confianza a la ciudadanía. De esta forma, la cuestión decisiva no es si el Estado debe o puede actuar con mayor intensidad que habitualmente. Tal "intensificación” no está permitida en un Estado de Derecho; el mismo, en palabras de Luhmann, prohíbe la identificación del fin con los medios ${ }^{72}$. La cuestión esencial es más bien la de si el Estado, obligado a acomodar su actuación a la ley y, en el marco de dicha legalidad, a adoptar una normación exhaustiva, y la bondad de cuyas intenciones se da por supuesta, se encuentra, precisamente sobre la base del razonamiento expuesto, vinculado por el deber de respetar las exigencias de forma y procedimiento de manera cualificada. Este rigor persigue garantizar la integridad normativa del sistema político; y sirve igualmente a la consecución de los propios fines, puesto que el Ejecutivo precisa de la confianza ciudadana para poder alcanzar aquellos.

Que las reflexiones expuestas trascienden la mera elucubración académica lo demuestran fenómenos diversos. En este sentido, cabe preguntarse si las protestas actuales contra las medidas estatales de lucha frente a la pandemia se han vuelto tan vehementes e irracionales justamente porque los procedimientos parlamentarios para la adopción de decisiones han resultado decepcionantes en los últimos meses. Precisamente allá donde los mismos eran factibles han contado poco, puesto que la capacidad de decisión se ha desplazado hacia el Ejecutivo. Tal especulación cumple, en todo caso, una función jurídico-constitucional central desde la perspectiva de los procedimientos parlamentarios: los mismos responden, en último término, a la necesidad de proporcionar a la minoría una plataforma institucional e integrarla así en el sistema. Lo anterior exige, claro está, que las decisiones se adopten en el ámbito parlamentario. De nuevo como recordatorio: en los últimos meses, no se ha celebra-

71 A este respecto, cfr. la inigualable exposición de Gehrard Lehmbruch, Parteienwettbewerb im Bundesstaat, 3. ${ }^{\mathrm{a}}$ ed., 2000; vid. asimismo Florian Meinel, Vertrauensfrage, 2019.

72 Luhmann, VerwArch 56 (1965), pp. 301, 308. 
do un solo debate en el Parlamento sobre los fundamentos jurídicos materiales de las medidas adoptadas en el marco de la lucha contra la pandemia. El Parlamento, por el contrario, asumió la interpretación de que la modificación de las habilitaciones previstas en la IfSG habría sido introducida "para dotar a la normativa de una mayor claridad" 73 .

Con mayor evidencia se manifiesta la conexión existente entre la necesaria confianza de la ciudadanía y los límites a la protección de datos personales. Si se consideran válidas las extralimitaciones en el tratamiento de datos generados a partir de la lucha contra la pandemia — por ejemplo, en el ámbito de la gastronomía— para la persecución general de los delitos, no pueden sorprender las declaraciones falsas ${ }^{74}$. En este contexto convergen la inobservancia del marco legal y la falta de clarividencia política. La regulación en materia de protección de datos refuerza, precisamente, la fiabilidad de las bases de datos estatales, lo que no sorprende a los conocedores de la literatura sociológico-jurídica ${ }^{75}$.

La referida conexión resulta jurídicamente tangible, en fin, si se considera la forma en que los Estados federados han procedido a la adopción de medidas restrictivas. Los ejecutivos de algunos Länder han desarrollado, en primer lugar, intervenciones de alcance general mediante la aprobación de actos administrativos cuyos potenciales destinatarios se contaban por millones, lo que desembocó en el recurso al Reglamento como forma estándar de actuación. Estos reglamentos comparten, sin embargo, con los actos administrativos de alcance general su incidencia directa sobre los derechos de los destinatarios y la innecesariedad de ulteriores trámites administrativos. Ciertamente, desde una perspectiva material, son auténticos actos administrativos agregados. Esto no deja de resultar problemático, por cuanto el ordenamiento impone exigencias procedimentales y de motivación diferentes en función del tipo de actuación. En este sentido, el deber de motivación de los actos administrativos tan solo se excepciona en los supuestos en que los mismos despliegan efectos jurídicos generales ( $\$ 39.2$, apdos. 3 y 5, de la VwVfG - Ley de Procedimiento Administrativo), mientras que la adopción de reglamentos no requiere de motivación en ningún caso ${ }^{76}$. Estos encuentran su justificación, ante todo, en las correspondientes habilitaciones legales, rara vez, en el Derecho alemán, en las especialidades del procedimiento $^{77}$. Las leyes, por lo general, tampoco precisan de motivación; las mismas son el resultado de un procedimiento discursivo, en el que se ponen de manifiesto las diferentes posiciones representadas en el Parlamento, de manera que se posibilita la comprensión de diferentes problemas políticos, conectados entre sí, a través de la Ley.

73 BT-Drucks. 19/18111, p. 24.

74 https://www.sueddeutsche.de/bayern/corona-bayern-gaesteliste-polizei-herrmann-14971971.

75 Niklas Lubmann, Funktionen und Folgen formaler Organisation, 4. ${ }^{a}$ ed., 1995; Arthur L. Stinchcombe, When Formality Works, 2001.

76 Sobre los motivos de dicha diferenciación, Christoph Möllers, Gewaltengliederung, 2005, pp. 189 y ss.

77 Johannes Saurer, Die Funktionen der Rechtsverordnung, 2010. 
Las medidas adoptadas en el marco de la lucha contra la pandemia constituyen, en la práctica, actos administrativos generales carentes de motivación que incorporan limitaciones de derechos muy intensas, y cuyo único soporte viene representado por las ruedas de prensa en las que los mismos eran anunciados de manera superficial. Paralelamente, de las discusiones centrales planteadas entre los gobiernos de la Federación y de los Länder tan solo se ha dado noticia a través de anecdóticas notas de prensa. El que el referido no era tan solo un problema estético quedó evidenciado en la fase de control jurisdiccional de los reglamentos, cuya intensidad aumentó considerablemente, puesto que no resultó tarea fácil a la jurisdicción contenciosoadministrativa la fijación de una interpretación constructiva de medidas restrictivas adoptadas sin justificación formal. ¿Hasta qué punto han sido útiles las medidas de contención para la protección de la salud pública? ¿Es suficiente el mantenimiento de la distancia social, o es más efectivo, por el contrario, evitar las aglomeraciones y los lugares en que se incrementan los riesgos de infección? ${ }^{78}$ Precisamente en el momento en que la práctica totalidad de limitaciones fueron sustituidas por un complejo régimen de excepción, la falta de motivación trajo consigo problemas desde la perspectiva del principio de igualdad y condujo a la anulación o a la interpretación restrictiva de numerosas disposiciones reglamentarias. También en este punto el rigor procedimental habría sido el medio más eficaz; sin embargo, el mismo solo habría podido alcanzarse a través de la intervención del legislador parlamentario. La crisis, sin embargo, ha provocado una vulgar oposición, solo teórica, entre la observancia de las formas y la efectividad de la regulación.

\section{CONCLUSIONES}

El papel del criterio científico ha sido objeto de discusión pública durante la crisis, puesto que resultaba imposible interpretar una situación desconocida sin recurrir a la pericia de los especialistas. Algunas posiciones, en absoluto novedosas, recuperaron su visibilidad: la Ciencia puede aportar información, pero no puede asumir la responsabilidad derivada de las decisiones políticas adoptadas por recomendación suya. Esta información debía facilitarse a la ciudadanía, no solo a gremios cerrados, y había de transmitirse adecuadamente el carácter provisional e incierto del conocimiento científico actual. Al mismo tiempo, se puso de manifiesto que la Ciencia puede asumir una obligación política de comunicarse con la ciudadanía, de difundir el estado del conocimiento, de exponerlo con claridad y popularizarlo.

Las referidas posturas presentan diversas implicaciones para el Derecho constitucional. En primer lugar, la organización del asesoramiento científico del Estado es un problema recurrente para el Derecho constitucional ${ }^{79}$. Debe aún analizarse qué enseñanzas es posible extraer de la experiencia, también desde la perspectiva del

78 Al respecto, cfr., por ejemplo, VGH Mannheim, 5.6.2020 - 1 S 1623/20, http://lrbw.juris.de/ cgi-bin/laender_rechtsprechung/document.py?Gericht=bw冈nr=31431.

79 Andreas Voßkuhle, en: Handbuch des Staatsrechts, tomo III, 3. ${ }^{\mathrm{a}}$ ed., 2005, $\$ 43$. 
Derecho (constitucional) comparado. El análisis del sistema de asesoramiento secreto del gobierno británico pone de manifiesto hasta qué punto es posible abusar de la invocación del criterio científico. El ejemplo sueco demuestra que la creación de una estructura administrativa desvinculada de las responsabilidades políticas contribuye a la resolución de tales problemas. Desde otra perspectiva, se plantea la cuestión relativa al papel de la propia Ciencia del Derecho público en el debate. La extraordinaria presencia de constitucionalistas en la prensa diaria fue advertida y, como se ha expuesto, también en ocasiones lamentada, ya por su carácter superfluo, ya por lo neurótico de sus puntos de vista ${ }^{80}$. Esta crítica se confundió con un escepticismo, extendido en la disciplina, en relación con la participación en formatos populares e híbridos, como, por ejemplo, los blogs científicos.

Rectamente entendida, esta crítica, particularmente si se basa en los motivos referidos, no puede compartirse, en tanto que el acto de dirigirse a la ciudadanía daba respuesta a la inquietud manifestada por la misma, y fue generalmente recibido con favor. Los autores del presente trabajo son incapaces de recordar cuántas preguntas les dirigieron personas interesadas, periódicos e incluso autoridades públicas durante la primera fase de la pandemia. Las opiniones publicadas en blogs fueron rápidamente asumidas y citadas tanto en ensayos científicos como en dictámenes de funcionarios públicos, e incluso en resoluciones judiciales. La valoración que mereció la oferta hizo que la demanda se mantuviera. No explicitar aquellas opiniones en nombre de una pretendida lealtad ciudadana o de la integridad científica habría sido una decisión equivocada, máxime en una época caracterizada por una extraordinaria y general incertidumbre.

Precisamente las entradas de blog se presentan hoy como un formato consolidado que se sitúa a caballo entre los ensayos periodísticos y los publicados en revistas científicas $^{81}$, en el que se trabaja con plazos relativamente breves, con limitaciones de espacio menos severas y, en ocasiones, con evidencias científicas. Desde la perspectiva del plan de trabajo, este formato se basa en sus propias normas. El hecho de que los constitucionalistas manifiesten, precisamente, su preocupación por la integridad científica de su disciplina no deja de resultar irónico, toda vez que el Derecho constitucional es susceptible de un tratamiento muy limitado conforme a una lógica estrictamente científica. Autores y destinatarios del Derecho constitucional son todos los ciudadanos. La emancipación del Derecho constitucional como disciplina parece, en el contexto actual, difícilmente evitable; la misma representa, en una democracia, un problema que debe ser combatido a través de un proceso de mediación científica. Lo anterior es especialmente cierto en el caso de la dogmática sobre los derechos fundamentales. Los mismos no son tan solo el producto de un control judicial

\footnotetext{
80 Hase, JZ 2020, pp. 697 y ss.

81 Desde la perspectiva de la integridad científica, debe subrayarse que la misma no depende de la forma de difusión por la que se opte. Incluso en una publicación reputada como la $J Z$ pueden detectarse citas descuidadas: así, por ejemplo, Hase, JZ 2020, pp. 697, 700, donde se exponen las tesis de Kingreen mediante una desafortunada comparación con la etapa final de la República de Weimar, aunque el autor, en sus conclusiones, se distancia con respecto a dicha comparación.
} 
de signo transformador. Sus presupuestos son el resultado de una discusión pública que impregna significativamente los parámetros de control. Esto se manifiesta con especial intensidad en la praxis fiscalizadora de los últimos meses, eminentemente descentralizada.

Pero no solo la integridad científica, sino también la lealtad política parece ser la causa del malestar. En una situación de emergencia existiría una suerte de obligación ciudadana, que se impondría con especial rigor a los constitucionalistas, de acuerdo con la cual unos y otros habrían de abstenerse de expresar sus sesgadas reflexiones a fin de no poner en peligro el proyecto común de la lucha contra la pandemia, incluso por consideración a la responsabilidad que corresponde a las instancias decisorias. En relación con tales posicionamientos, es preciso no caer en una ironía precipitada; se debe, por el contrario, reflexionar sobre la posible existencia de contextos en los que aquellos puedan resultar oportunos. Tal conclusión exige, en primer término, considerar la forma en que se manifiesta la crítica científica: con conciencia de la gravedad de la situación y de los dilemas que se plantean en la toma de decisiones, renunciando a toda tentación autoritaria. Por otra parte, adoptar una postura excesivamente tímida sería demostrativo de un inexplicable desdén por las instituciones de la Ley Fundamental, así como por el poder estatal constituido sobre su base. También en los Estados democráticos se ejerce el poder, y toda dominación ha de someterse a crítica. Un escenario en el que las instancias de poder se replegaran en aras de la defensa del orden no sería en modo alguno deseable. La crítica puede ser una forma de lealtad ${ }^{82}$.

${ }^{82}$ Klaus Mertes, Widerspruch aus Loyalität, 2009. 